http://www.jfas.info

\title{
THE EFFECT OF O-CHLOROBENXYLIDENE MALONONITRITE (CS) TO MILITARY PERSONALS HEALTHFURING NBC TRAINING
}

\author{
M. Vikneswaran ${ }^{*}$ and N. A. Majid \\ Department of Civil Engineering, Faculty of Engineering, UniversitiPertahananNasional \\ Malaysia, Sungai Besi Camp, 57000 Kuala Lumpur, Malaysia
}

Published online: 10 September 2017

\begin{abstract}
o-ChlorobenzylideneMalononitrile (CS) is a riot control agents (RCAs) that is a non-lethal compound that has relatively short onset and limited duration of action by temporarily incapacitating human through irritating the skin and mucosal membranes on eyes, airways and digestive tract. This research was aimed to find out whether military personnel in Malaysian that is exposed to CS in a confined gas mask facility during a gas mask testing training would affect the respiratory health, especially the lung health symptoms manifested and their lung functions. A total of 58 military personnel participated in this study where 29 of them are NBC trainers and 29 others are the control group. The experiment was conducted onto participants via interview using a standardized Medical Research Clinical Questionnaire (MRCQ) (UK) 1986 and spirometer method for lung function tests.
\end{abstract}

Keywords: riot control agents (RCAs); confined gas mask facility; forced volume capacity (FVC); forced expiratory volume $\left(\mathrm{FEV}_{1}\right)$; chronic obstructive lung disease (COPD).

Author Correspondence, e-mail: vikneswaran@upnm.edu.my

doi: http://dx.doi.org/10.4314/jfas.v9i3s.47 


\section{INTRODUCTION}

Riot control agents (RCAs) is a nonlethal compound that has relatively short onset and limited duration of action by temporarily incapacitate through irritating the skin, mucosal membranes on eyes, airways and digestive tract thus making it an effective agents used by military to simulate and train personnel of preparedness to act against chemical weapon attack [17].The level of o-ChlorobenzylideneMalononitrile (CS) concentration is not only major concern in public area as riot controls, but also during training purpose inside the military gas mask training facilities [1-2]. Since then RCAs has revolutionised, whereby the World War I (WWI) between German and French has marked the birth of RCAs such as Acrolein (Papite), Chloropicrin (PS) and Diphenylaminearsine (DM; Adamsite) [17]. Later, at the end of WWI, the US has experimented on the use of $\mathrm{CN}$ as RCAs and became widely used up until World War II (WWII) [16]. The formulation of CS as RCAs came only in 1959, as it is more chemically stable compound and more potency with less toxicity than $\mathrm{CN}$. o-ChlorobenzylideneMalononitrile (CS) replaced $\mathrm{CN}$ as preferred RCAs and was widely deployed during the war to flush the Viet Cong out of their underground hidings; bunkers and tunnels [17]. Today, CS is being commonly adopted by militaries which also includes Malaysian Armed Forces (MAF) for riot control training, respirator testing in gas mask facilities and simulation for combat preparedness against Chemical Weapons (CW) environment. The level of o-ChlorobenzylideneMalononitrile (CS) concentration is not only major concern in public area as riot controls but also during training purpose inside the military gas mask training facilities [1-2]. Organization for the Prohibition Chemical Weapon (OPCW) specifies Chemical Weapon Convention (CWC) under Article IV regarding Riot Control Agents (RCAs) states that States Parties are to declare to the Organisation for the Prohibition of Chemical Warfare (OPCW), the riot control agents (RCAs) that they have in possession [10]. o-ChlorobenzylideneMalononitrile (CS) is a lachrymator that causes tearing (watering of the eyes) that can effect a human through inhalation [3]. o-ChlorobenzylideneMalononitrile (CS) can cause primary and allergic contact dermatitis, skin burns and factors influencing the severity varies [5]. There are also reported cases of CS inducing symptoms of lung injury indicative of reactive airways dysfunction syndrome 
(RADS) [9]. In [6] concluded from their study on military personnel that after exposure to intolerable amount of CS concentration of $5 \mathrm{mg} / \mathrm{m}^{3}$ the recovery period will be 15 to 30 minutes but a few onset signs can persist slightly longer depending on individuals. However, military personnel can also be exposed to unusually high doses and medical injuries from conditions of excessive application of agents, delivery in enclosed spaces (gas mask facilities), prolonged exposure (confidence test mask or no way to flee), high temperature and relative humidity (skin reaction).

Various case studies has shown that exposure to CS or commercially known as tear gas can adversely affect the lung health and respiratory of subjects that comes into contact with CS vapour [6]. In Malaysian Army, trainers are exposed to CS during gas mask testing training for Nuclear, Biological and Chemical (NBC) defence collective training. It is a compulsory training that every military personnel in army required to attend and retrained from time to time in order to be competent when deployed in NBC environment [14]. Training is conducted in a closed room or confined space of the mask testing facility or gas chamber to test gas mask operability [7]. The facility engineering designed is to facilitate the NBC gas mask testing training with open space of 64 meters cubic $\left(\mathrm{m}^{3}\right)$. The NBC unit is a designated unit that is given responsibility to conduct collective training for the purpose of NBC warfare. Since its formation on 1st April 2002 has successfully trained a total of 5,000 personnel from various units in the Malaysian. Due to that, only military personnel amongst the engineer corps that are trained and undergoes specialization in NBC field are qualified to be posted into this unit and become trainers or staff. The trainers and staffs are stationed in this particular unit for extended period between minimum 3 years until 10 years. Random interviews conducted amongst the trainers has indicated that they are experiencing multiple health difficulties ranging from respiratory to skin reaction from direct contact to CS. Studies done by [1] shows that frequent exposure to tear gas can increase respiratory system and has prolonged effects on the pulmonary system. o-ChlorobenzylideneMalononitrile (CS) is also known to cause irritation to nose and mouth and sometimes to the skin, particularly in moist and warm areas whereby after six hours exposure to CS an individual may experience blister, eczema and oedema [4]. Even so, the NBC trainers whom experienced such symptoms never 
reported or consult any medical assistance from physician as lack of awareness about the effects of the CS to human directly. As for now, there has not been any extensive study done on NBC trainers involved in NBC gas mask testing in Malaysia to determine the health effects of the aftermath from CS exposure. Shortcoming from lack of exposure control, health monitoring, proper Standard Operating Procedures (SOPs) and chemical handling knowledge could arise various health concern to the trainers and NBC trainees especially after a prolong period of exposure to CS aerosol and vapour. Studies need to be conducted to investigate the effects of this condition and control measures need to be suggested. Given the reason above, this study has presented theoretical model to address the main objectives of presenting the result from the studies of respiratory health amongst personnel undergoing NBC gas mask testing. The type of this quantitative research is a descriptive cross-sectional and inferential analysis in exploring relationship between variables study through statistical techniques in summarizing the information collected from questionnaires using internationally approved MRCQ (UK) 1986 and lung function testing using stationary Spiro lab II spirometer instrument. This study was directed to fulfil the research objective which is to find out whether military personnel involved in gas mask testing training that has been exposed to CS vapour exhibits any problems in respiratory health. There are three indicators in the study that was applied in deciding the status of the military personnel's respiratory health. The three indicators that was selected is forced vital capacity $(\mathrm{FVC})$, forced expiratory volume $\left(\mathrm{FEV}_{1}\right)$ and lung health symptoms. The symptoms that was identified to determine the lung health symptoms of this research are breathlessness, wheezing, cough, phlegm and chest illnesses.

It is hypothesized that there is a probability that NBC trainers that was involved in gas mask testing training would have lower; $\mathrm{FVC}$ and $\mathrm{FEV}_{1}$ and higher lung problem symptoms as compared to control group. Even though both work group works in the same area but the environment and nature of job sets the level of contact with CS. Therefore, it is expected that military personnel involved in gas mask testing training probably have lower lung function and exhibits more lung health problem symptoms as compared to the control group. The overall theoretical relationships between the variables of this study are depicted in Fig. 1. 


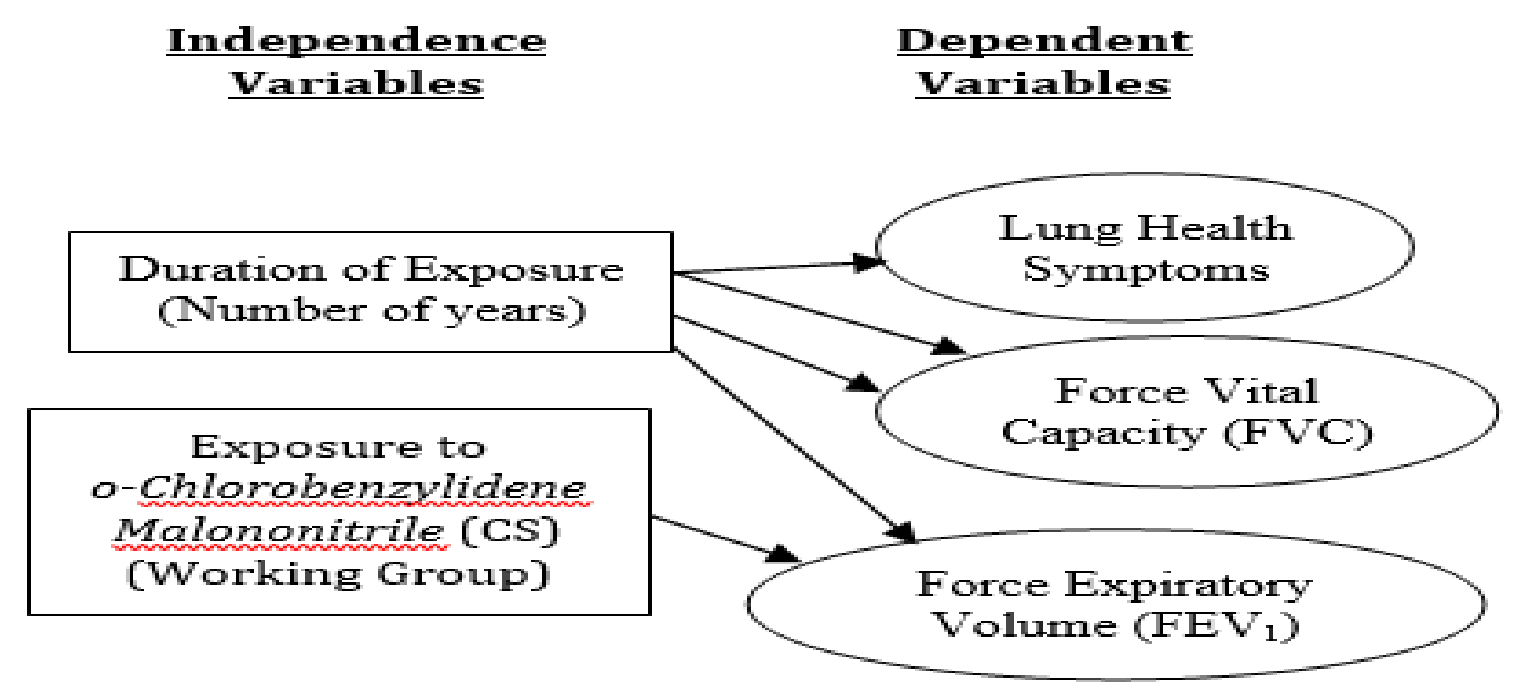

Fig.1. Illustrates the relationships between variables that were tested in this study

This research was conducted to experiment and investigate five main hypotheses. The first hypotheses were hypothesized to study the difference in lung health symptoms between NBC trainers and control group that is divided into breathlessness and wheezing, cough, phlegm, period of cough and phlegm and chest illnesses. The second and third hypotheses was directed to find the difference between NBC trainers and control group for indices of lung function which includes FVC and $\mathrm{FEV}_{1}$. The last two hypotheses which is hypotheses four and five is set to investigate on the relationship of lung function for $\mathrm{FVC}$ and $\mathrm{FEV}_{1}$ of $\mathrm{NBC}$ trainers with duration of exposure to CS in gas mask testing training.

\section{EXPERIMENTAL}

The chosen analysis method consisting of MRCQ (UK) 1986 questionnaires and spirometer testing was conducted on all 58 participants which includes studied group; trainers and control group; supporting staffs and staffs from adjacent unit. The spirometer test and questionnaires was carried out onto participant after the participant has read, understood, signed the consent letter that was distributed to the participant individually and briefed of the purpose of the study one day ahead before the initial training was executed. Participants were gathered in the main lecture hall at the NBC unit and given the MRCQ (UK) 1986 questionnaires to be completed. The answering process of the questionnaires was guided by the researcher as they concurrently answer each question. The participants were guided while answering the MRCQ (UK) 1986 questionnaires form to allow the participant clear 
understanding of each questions in the questionnaires. The batch of data collection consist of 58 personnel. After all the participants completed the questionnaires answering session, they will report to the base military hospital before and after exposed to CS in gas mask facility to get their lung tested using spirometer to examine two parameters for $\mathrm{FVC}$ and $\mathrm{FEV}_{1}$. The participants were briefed and reminded to obey the do's and don'ts before undergo the spirometer test which includes avoiding alcohol for at least four hours, avoid eating substantial meal, avoid smoking an hour before and to wear loose fitting clothing [13]. Once this cycle of process is completed starting from consent form signing to the final second, spirometer reading the data collection process is completed. All the data collected will be further analyzed based on the hypothesis to determine the difference and relationship studied.

\subsection{Medical Research Council Questionnaire (MRCQ) UK 1986}

This study applied approved MRCQ (UK) 1986 questionnaires to research and analyze on lung health symptoms differences between trainers with control group. The second instrument applied in this research were in the form of questionnaire sheet, which is designed based on the extensively validated Medical Research Council Questionnaire (MRCQ) UK 1986. The initial MRCQ consisted of 25 questions, whereby for the purpose of this research three questions were added in relation to duration factor of CS exposure. This questionnaire is a tool to study respiratory epidemiology in communities and occupational group and reliably that is related to symptoms and lung function. It comprises questions on respiratory symptoms; cough, phlegm, breathless, wheezing and chest illness and detailed questions on smoking history and check list on past illnesses. Pilot testing were done on the additional questions by thirty personnel to validate the questionnaires. The questionnaires were distributed to all three work groups to get information for self-scaled severity of the respiratory problems which might be associated with their working condition. Each military personnel selected in this research are guided by researcher as they answer all 28 question in the questionnaires.

\subsection{Gas Mask Facility}

The research is carried out in a confined room environment that is utilized only for the purpose of gas mask testing training. It is a $64 \mathrm{~m}^{3}$ room that is exposed to CS released from either smoke grenade containing of $130 \mathrm{~g} \mathrm{CS}$ or burning $0.5 \mathrm{~g}$ of CS pallet. The ignition of the 
CS grenade or burning of CS pallet is practice in order to release vapour or aerosol like CS into the gas mask testing room. The purpose of the mask testing is to instil confidence in the protective capability of the military protective mask when deployed in combat area with probability of chemical threats. o-ChlorobenzylideneMalononitrile (CS) in normal temperature is a crystalline solid with a pepper-like odour and heat assist in the dispersion process by vaporizing the CS, which then condenses to form an aerosol. In [6] further identified that CS released may product CS derived compounds and other thermal degradation product formed during heat dispersal that raised questions about the potential health risks associated with heat dispersal devices particularly in enclosed spaces.

\subsection{Spiro Lab II Spirometer Instrument}

This research studied the respiratory function of 58 samples that are involved directly (trainers) and indirectly involved (control group) with NBC gas mask testing training. Instruments that was applied in this study is a spirometer test using a stationary Spiro lab II spirometer instrument. The parameters collected from the spirometer test with the instrument are forced vital capacity $(\mathrm{FVC})$ and forced expiratory volume $\left(\mathrm{FEV}_{1}\right)$. Auxiliary equipment for spirometer test includes 58 units of disposable mouth pieces, printer papers, a desk top and nose clip. The WinspiroPRO software analysis and measures the air flow from each individual as he or she blows into the mouth piece that is connected to the Spiro lab II instrument. The result for $\mathrm{FVC}$ and $\mathrm{FEV}_{1}$ were automatically enlisted in numerical figures on the computer monitor. The results were printed out and file according to the work group.

\section{RESULTS AND DISCUSSION}

As shown in Table 1, the descriptive analysis onto 58 selected respondents are made of 29 trainers from the military unit consisting of one female trainer that conducts the NBC course. The other 29 all male participants as control group originating from two adjacent units that is collocated outside the 200 meters radius from the gas mask facility. The respondents selected for this study showed that the age group that contributes to majority of respondents is within age group of 28-37 years old with 26 respondents each $(n=26,44.8 \%)$. The second largest respondents' age group in this study is between the ages of 18-27 years old with the total of 11 
respondents $(n=11,19 \%)$. The study does not have respondents among the age group of 48-57 years old. The scale of service tour in respective units is divided in three main group which is duration of service one to three years, four to six years and seven to ten years. The scale of service between four to six years shows the highest number of percentage of $53.5 \%(n=31)$. Whilst, the lowest service years is between one to three years consisting of seven trainers and two controls. The scale for service age between seven to ten years counts for $31 \%$ of the overall respondent count $(\mathrm{n}=58)$. The frequency of respondents exposed to o-ChlorobenzylideneMalononitrile (CS) are divided into three main groups. The no exposure scale dominates $50 \%(n=29)$, whereby the numbers of respondents all comes from control group. The scale with exposure less or equal to twice records the lowest numbers of respondents $(n=9,15.5 \%)$ and all the respondents are from trainer's group. The rest of twenty $(n=20)$ respondents of trainer's group that have not been accounted for records the frequency of exposure more than twice per week with percentage of $34.5 \%$. The tobacco smoking habits amongst the respondents consist of three main factors. This descriptive analysis for the tobacco smoking habits takes count of all the 58 respondents. The first factor is classification of smokers amongst the respondent whereby 38 are smokers. The second factor that is the non-smoker as shown in the table below indicated that there are 17 non-smoking and only three ex-smoker participants.

\subsection{Lung Problem Symptoms}

According to Table 2, trainer's group showed slightly higher score as compared to the control group with average score of 2.30 for trainers and 1.55 for control group. The highest reported symptom is phlegm with 2.59 in trainers and 2.03 in control group, followed by cough and chest illnesses which both scores the same average with 2.38 and 1.55 respectively. The least reported symptoms are breathlessness and wheezing with 1.86 and 1.07. The results indicate that, the occurrences of the symptoms, which scored 2.11 for trainer's group and 1.46 for control group and falls between the regions of very rare or rare region for both groups. The higher average lung health symptoms problems might trigger that respondents from trainer's group have higher tendency to have respiratory health problem as compared to the army personnel from control group. 
Table 1. Demographic Characteristic of Respondents

\begin{tabular}{|c|c|c|c|c|}
\hline \multirow{2}{*}{ Samples } & \multicolumn{3}{|c|}{ Respondents } & \multirow[t]{2}{*}{$(\%)$} \\
\hline & Total & Male & Female & \\
\hline \multicolumn{5}{|c|}{ Workplace and Gender } \\
\hline NBC Trainers & 29 & 28 & 1 & 50 \\
\hline Control Group & 29 & 29 & 0 & 50 \\
\hline \multicolumn{5}{|c|}{ Age Distribution } \\
\hline $18-27$ & 11 & 11 & 0 & 19 \\
\hline $28-37$ & 26 & 25 & 1 & 44.8 \\
\hline $38-47$ & 21 & 21 & 0 & 36.2 \\
\hline $48-57$ & 0 & 0 & 0 & 0 \\
\hline \multicolumn{5}{|c|}{ Years of Service } \\
\hline $1-3$ & 9 & 9 & 0 & 15.5 \\
\hline $4-6$ & 31 & 30 & 1 & 53.5 \\
\hline $7-10$ & 18 & 18 & 0 & 31 \\
\hline \multicolumn{5}{|c|}{ Frequency of Exposure } \\
\hline No Exposure & 29 & 29 & 0 & 50 \\
\hline$\leq$ twice & 9 & 8 & 1 & 15.5 \\
\hline$>$ twice & 20 & 20 & 0 & 34.5 \\
\hline \multicolumn{5}{|c|}{ Smoking Habit } \\
\hline Smoker & 38 & 38 & 0 & \\
\hline Non-Smoker & 17 & 16 & 1 & \\
\hline Ex-Smoker & 3 & 3 & 0 & \\
\hline
\end{tabular}


Table 2. Occurrence of lung problem symptoms amongst respondents

\begin{tabular}{ccc}
\hline Lung Problem Symptoms & $\begin{array}{c}\text { Average Scale of Occurrence } \\
\text { Trainers }\end{array}$ & Controls \\
\hline Breathlessness and Wheezing & 1.86 & 1.07 \\
Cough & 2.38 & 1.55 \\
Phlegm & 2.59 & 2.03 \\
Period of Cough and Phlegm & 1.34 & 1.10 \\
Chest Illnesses & 2.38 & 1.55 \\
Overall Average & 2.11 & 1.46 \\
\hline
\end{tabular}

\subsection{Lung Function Test}

The mean of height and weight of trainer's group is $167.2 \mathrm{~cm}$ and $72 \mathrm{~kg}$, whilst for control's group are $169.2 \mathrm{~cm}$ and $69.6 \mathrm{~kg}$ respectively. The body surface area (BSA) from the trainer's group that is 1.83 is higher than BSA recorded for respondents from control group. Table 3 depicted that all three aspects displayed reading for respondents coming from control group of 4.19 for predicted FVC, higher measured FVC of 2.15 and 51.6 for percentage of FVC as compared to trainer's group which is 4.59 for predicted FVC, 2.14 for measured FVC and 46.7 for percentage of FVC. The reading for forced expiratory volume $\left(\mathrm{FEV}_{1}\right)$ from the Table 3 showed that percentage of $\mathrm{FEV}_{1}$ for respondents from trainer's group are lower than respondents from control group that is $55.09 \%$ as compared to control $61.25 \%$. The predicted and measured $\mathrm{FEV}_{1}$ for control group are 3.49 and 2.14 respectively. This result showed that the trainers has lower lung function ability making them incapable of holding high air capacity as compared to the control group. Demographic factors like mean height $(\mathrm{cm})$, weight $(\mathrm{kg})$, Body Surface Area (BSA) can also influence the reading for FVC predicted, FVC measured and percentage of FVC (\%). 
Table 3. Mean for lung function test of respondents

\begin{tabular}{ccc}
\hline Mean & Trainers & Controls \\
\hline Height (cm) & 167.2 & 169.2 \\
Weight (kg) & 72.0 & 69.6 \\
Body Surface Area (BSA) & 1.83 & 1.81 \\
FVC Predicted & 4.59 & 4.19 \\
FVC Measured & 2.14 & 2.15 \\
FVC (\%) & 46.7 & 51.6 \\
FEV $_{1}$ Predicted & 3.86 & 3.49 \\
FEV $_{1}$ Measured & 2.12 & 2.14 \\
FEV $_{1}(\%)$ & 55.09 & 61.25 \\
\hline
\end{tabular}

3.3. Difference of Lung Health Symptoms between Military Personnel and Control

\section{Group}

The independent t-test outcome for breathlessness and wheezing for military personnel $(\mathrm{M}=$ $1.86, \mathrm{SD}=1.25 ; \mathrm{t}(58)=3.28)$ involved in $\mathrm{NBC}$ gas mask testing training and control group $(\mathrm{M}=1.07, \mathrm{SD}=0.37, \mathrm{p}=0.02(<0.05)$, two tailed $)$ has moderate differences in the means (mean difference $=0.79,95 \% \mathrm{Cl}: 0.30$ to 1.28$)$, which (eta square $=0.06$ ) indicates medium effect. Analysis for cough symptom reveals that cough symptom between military personnel $(\mathrm{M}=2.38, \mathrm{SD}=1.47 ; \mathrm{t}(58)=2.41)$ involved in NBC gas mask testing training and control group $(\mathrm{M}=1.55, \mathrm{SD}=1.12, \mathrm{p}=0.02(<0.05)$, two tailed $)$ has small magnitude of the differences in the means (mean difference $=0.83,95 \% \mathrm{Cl}: 0.14$ to 1.52 ), which (eta square $=$ 0.04) indicates small effect. The third symptoms observed occurring is chest illnesses, whereby the symptoms between military personnel $(\mathrm{M}=2.59, \mathrm{SD}=1.32 ; \mathrm{t}(58)=1.66)$ involved in NBC gas mask testing training and control group $(\mathrm{M}=2.03, \mathrm{SD}=1.21, \mathrm{p}=0.02$ $(<0.05)$, two tailed) show a small magnitude of the difference in the means (mean difference $=0.33,95 \% \mathrm{Cl}:-0.12$ to 1.22$)$ which $($ eta square $=0.03)$ indicates small effect. The other two symptoms observed in this study which are phlegm and period of cough and phlegm found not occurring among the respondents that are exposed to NBC gas mask testing training. The analysis show that no significant difference of phlegm symptoms between military personnel 
$(\mathrm{M}=2.59, \mathrm{SD}=1.32 ; \mathrm{t}(58)=1.66)$ involved in $\mathrm{NBC}$ gas mask testing training and control group $(\mathrm{M}=2.03, \mathrm{SD}=1.21, \mathrm{p}=0.10$, two tailed), whereby the magnitude of the differences in the mean is small (mean difference $=0.33,95 \% \mathrm{Cl}:-0.12$ to 1.22 ) which (eta square $=0.03$ ) indicates small effect. It goes the same for period of cough and phlegm whereby no significant difference between military personnel $(\mathrm{M}=1.34, \mathrm{SD}=0.89 ; \mathrm{t}(58)=1.37)$ involved in NBC gas mask testing training and control group $(\mathrm{M}=1.10, \mathrm{SD}=0.31, \mathrm{p}=0.18$, two tailed) with small differences in the mean (mean difference $=0.24,95 \% \mathrm{Cl}:-0.12$ to $0.59)$, which (eta square $=0.03)$ indicates small effect.

Table 1.Inferential analysis for differences of lung health symptoms between military personnel and control group $(\mathrm{M}=$ Mean, $\mathrm{SD}=$ Standard Deviation, $\mathrm{P}=$ Probability, $\mathrm{ES}=\mathrm{Eta}$

Square)

\begin{tabular}{cccccc}
\hline Symptoms & M & SD & P & t (58) & ES \\
\hline Breathless \& Wheezing & $1.86^{*}$ & $1.25^{*}$ & 0.02 & 1.66 & 0.06 \\
& $1.07^{* *}$ & $0.37^{* *}$ & & & \\
Cough & $2.38^{*}$ & $1.47^{*}$ & 0.02 & 2.41 & 0.04 \\
& $1.55^{* *}$ & $1.12^{* *}$ & & & \\
Chest Illnesses & $2.59^{*}$ & $1.32^{*}$ & 0.02 & 1.66 & 0.03 \\
& $2.03^{* *}$ & $1.21^{* *}$ & & & \\
Phlegm & $2.59^{*}$ & $1.32^{*}$ & 0.10 & 1.66 & 0.03 \\
& $2.03^{* *}$ & $1.21^{* *}$ & & & \\
Perioud Cough \& Phlegm & $1.34^{*}$ & $0.89^{*}$ & 0.18 & 1.37 & 0.03 \\
& $1.10^{* *}$ & $0.31^{* *}$ & & & \\
\hline
\end{tabular}

*Trainers, ** Control Group

\subsection{Difference of Forced Vital Capacity (FVC) and Forced Expiratory Volume (FEV $)_{1}$} between Military Personnel and Control Group

The overall independent t-test shows that there is no significant difference of Force Vital Capacity $(\mathrm{FVC})$ between military personnel $(\mathrm{M}=46.73, \mathrm{SD}=8.27$; $\mathrm{t}(58)=1.70)$ involved in NBC gas mask testing training and control group $(\mathrm{M}=51.16, \mathrm{SD}=11.32), \mathrm{p}=0.09$, two tailed). The magnitude of the difference in the mean (mean difference $=4.43,95 \% \mathrm{Cl}:-0.79$ 
to 9.64) was small (eta square $=0.05)$ indicates small effect.

Table 5. Inferential analysis for difference of lung function between army personnel and control group( $\mathrm{M}=\mathrm{Mean}, \mathrm{SD}=$ Standard Deviation, $\mathrm{P}=$ Probability, $\mathrm{ES}=$ Eta Square $)$

\begin{tabular}{cccccc}
\hline Symptoms & M & SD & P & t (58) & ES \\
\hline Force Vital Capacity (FVC) & $46.73^{*}$ & $8.72^{*}$ & 0.09 & 1.70 & 0.05 \\
& $51.16^{* *}$ & $11.32^{* *}$ & & & \\
Force Expiratory Volume (FEV1) & $55.09^{*}$ & $10.15^{*}$ & 0.05 & 1.99 & 0.06 \\
& $61.25^{* *}$ & $13.25^{* *}$ & & & \\
\hline
\end{tabular}

*Trainers, ** Control Group

The inferential analysis on the lung function test using independent t-test showed that there is significant differences of $\mathrm{FEV}_{1}$ between army personnel $(\mathrm{M}=55.09, \mathrm{SD}=10.15$; $\mathrm{t}(58)=$ 1.99) involved in NBC gas mask testing training and control group $(\mathrm{M}=61.25, \mathrm{SD}=13.25, \mathrm{p}$ $=0.05$, two tailed). The magnitude of the differences in the means (mean differences $=6.17$, $95 \% \mathrm{Cl}:-0.04$ to 12.37 ) is small (eta square $=0.06$ ) indicates small effect.

\subsection{Correlation between Forced Vital Capacity (FVC) and Forced Expiratory Volume (FEV1) with Duration of Exposure}

The spirometer data collected from the respondent in determining the relationship between FVC Percentage reading of the NBC trainers and duration exposed to CS was investigated using Pearson product-moment correlation coefficient. The preliminary analyses were performed to ensure no violation of assumptions normality, linearity and homoscedasticity. There is a weak, negative correlation between the FVC percentage and duration of CS exposure as $\mathrm{r}=-0.52, \mathrm{n}=29$ and $\mathrm{p}<0.05(\mathrm{p}=0.04)$ with longer exposure duration associated with low FVC percentage reading amongst the NBC trainers.

Table 6. Inferential analysis for correlation of lung function between army personnel and control group ( $\mathrm{M}=$ Mean, $\mathrm{SD}=$ Standard Deviation, $\mathrm{P}=$ Probability)

\begin{tabular}{ccccc}
\hline Lung Function & M & SD & P & r \\
\hline Force Vital Capacity (FVC) & $46.74^{*}$ & $8.27^{*}$ & 0.04 & -0.52 \\
& $5.48^{* *}$ & $2.14^{* *}$ & & \\
Force Expiratory Volume (FEV1) & $55.09^{*}$ & $10.15^{*}$ & 0.04 & -0.25 \\
\hline
\end{tabular}




\section{$5.48 * * \quad 2.12 * *$}

\section{*Trainers, ** Control Group}

The spirometer data collected from the respondent in determining the relationship between $\mathrm{FEV}_{1}$ Percentage reading of the NBC trainers and duration exposed to CS was investigated using Pearson product-moment correlation coefficient. The preliminary analyses were performed to ensure no violation of assumptions normality, linearity and homoscedasticity. There is a weak, negative correlation between the FEV1 percentage and duration of CS exposure as $\mathrm{r}=-0.25, \mathrm{n}=29$ and $\mathrm{p}>0.05(\mathrm{p}=0.04)$ with longer exposure duration associated with low $\mathrm{FEV}_{1}$ percentage reading amongst the NBC trainers.

The spectrum of the research is to investigate the lung health of Army personnel among the NBC trainers that are exposed to o-ChlorobenzylideneMalononitrile (CS) by delving into the differences of respiratory health symptoms that can be detected and relationship of lung function of NBC trainers with duration of their involvement with gas mask testing training. The health symptoms that was studied includes five main symptoms such as breathlessness and wheezing, cough, phlegm, period of cough and phlegm and chest illnesses. The indices that is scaled in studying the lung function includes FVC and $\mathrm{FEV}_{1}$. This research was conducted to experiment and investigate five main hypotheses. The first hypotheses were hypothesized to study the difference in lung health symptoms between NBC trainers and control group that is divided into breathlessness and wheezing, cough, phlegm, period of cough and phlegm and chest illnesses. The breathlessness and wheezing, cough and chest illnesses research hypotheses were accepted but phlegm and period for cough and phlegm research hypotheses were rejected. The second and third hypotheses was directed to find the differences between NBC trainers and control group for indices of lung function which includes $\mathrm{FVC}$ and $\mathrm{FEV}_{1}$. The analysis done on both hypotheses indicates that second hypotheses for null hypotheses is accepted and third hypotheses for null hypotheses is rejected. The last two hypotheses which is hypotheses four and five is set to investigate on the relationship of lung function for $\mathrm{FVC}$ and $\mathrm{FEV}_{1}$ of $\mathrm{NBC}$ trainers with duration of exposure to $\mathrm{CS}$ in gas mask testing training. Analysis conducted to test fourth and fifth hypotheses indicates that both fourth and fifth research hypothesis was accepted. Overall this analysis for 
lung health symptoms showed that although the workers and the control groups came from the same community, from the same race, sharing almost identical lifestyle but as they are working in difference condition, there is a difference in their lung health as well. This result would also establish a connection of respiratory problem faced by NBC trainers exposed to CS via gas mask testing training. The self-scaled lung health symptoms done by 58 respondents via the survey questionnaires shows that all five symptoms occurrence scale for trainers are higher compared to control group.

The hypotheses on the lung function for index of FVC is to study the difference between the military personnel consisting of NBC trainers and randomly selected personnel that is scattered outside 200 meters' radius as control group. The data collected was obtained via spirometer testing method that gives out FVC reading based on the standards of Caucasian. By definition FVC means maximum volume of air which can be exhaled or inspired during either a maximally forced. According to [11], Asians have been found to have an FVC about ten to $20 \%$ lower than matched Caucasians. Therefore, the normal FVC standards for Asian ethnicity should be $79.6 \%$ for NBC trainers and control group is $80 \%$. The readings collected in this study indicated that the FVC reading are even lower than the standards set for normal healthy Asian. The analysis in this research showed that the FVC is $46.7 \%$ and control group are $51.6 \%$. Based on the standards set by [18], the FVC reading of the respondents are classified as developing a moderate COPD. The result in chapter four showed that the NBC trainers that are exposed to CS does not show any abnormalities in FVC reading as compared to the control group. Firstly, there is also the contributing factor of smoking habit among the respondents from both trainers and control group whereby $62.1 \%$ are smokers and $8.6 \%$ is ex-smoker that is known to cause respiratory problems. Lastly the height difference between NBC trainers group and control group whereby mean is $167.2 \mathrm{~cm}$ for NBC trainers and 169.2 $\mathrm{cm}$ for control group. The reading for FVC will also increase with increase of height of respondent [11]. This validates the finding in this research, whereby there is no significant difference between FVC of NBC trainers and control group. The readings collected in this study indicated that the $\mathrm{FEV}_{1}$ reading are even lower than the standards set for normal healthy Asian. Based on the standards set by [18], the $\mathrm{FEV}_{1}$ reading of the respondents are classified 
as developing a moderate COPD. After detail analysis was done the results showed that there is a significant difference in the lung function reading for $\mathrm{FEV}_{1}$ for $\mathrm{NBC}$ trainer indicating that the effect from the CS exposure. The data collected was obtained via spirometer testing method that gives out $\mathrm{FEV}_{1}$ reading based on the standards of Caucasian. The normal $\mathrm{FEV}_{1}$ standards for Asian ethnicity should be 3.73 for NBC trainers and control group is 4.08 . The readings collected in this study indicated that the $\mathrm{FEV}_{1}$ reading are even lower than the standards set for normal healthy Asian. The analysis in this research shows that the $\mathrm{FEV}_{1}$ is 2.12 and control group is 2.14. Based on the standards set by [18], the FVC reading of the respondents are classified as developing a moderate COPD. FVC will increase with age until about 20 years old in females and 25 years old in males and will decrease gradually as the age increases [11]. Demographic analysis of this study reveals that $96.2 \%$ from the total 28 respondents are after 25 years of age, mean age for NBC trainers 37.9 years old and mean age for control group is 29.4 years old. Firstly, the low reading of $\mathrm{FEV}_{1}$ recorded among the NBC trainers in this study is validated by the age factor whereby it gradually decreases with age. Secondly, there is also the contributing factor of smoking habit among the respondents from both trainers and control group whereby $62.1 \%$ are smokers and $8.6 \%$ is ex-smoker that is known to cause respiratory problems. Lastly, there is also the exacerbating factor of exposure to CS experienced by the NBC trainer from gas mask test training in the gas facility that contributes to the low readings in lung function test. In [19] described the case of a 22 years old male exposed to $\mathrm{CS}$ with his spirometer reading $\left(\mathrm{FEV}_{1} / \mathrm{FVC}\right)$ the previous year was $72 \%$,but two weeks after CS exposure he developed the symptoms of chest tightness since that exposure and examination revealed bronchospasm whereby his $\mathrm{FEV}_{1} / \mathrm{FVC}$ ratio was reduced to $58 \%$. This validates the finding in this research whereby there is a significant difference between $\mathrm{FEV}_{1}$ of $\mathrm{NBC}$ trainers and control group.

There has been little study of the effect to lung capacity based on the duration CS exposure but,[6] found that effects on human health from CS seem to be correlated with concentration and a dose-response pattern. In [12] tested the ability for human to work in a CS contaminated environment for duration of two weeks, whereby it is found that test subject accuracy decreases due to symptoms of respiratory failure. In [8] reported the case of a previously 
healthy infant who developed a respiratory problems following prolonged exposure to CS inside a confined area. The research on FVC reading with duration of exposure from o-ChlorobenzylideneMalononitrile (CS) among the NBC trainers in this study revealed that there is a negative relationship between the variables studies. It is found that FVC reading collected in this research will decreases as the duration of exposure to CS increases. Prolonged exposure high concentration of CS in confined spaces without proper ventilation can result to changes in respiratory tract and inflammatory associated to secondary infection. Research conducted on personnel who are NBC trainers exposed to CS indicates a negative relationship between lung function tests for FVC with duration of exposure to anti-riot agent. Studies on volunteers indicate that exposure to about 0.5 to $1 \mathrm{mg} / \mathrm{m}^{3} \mathrm{CS}$ for 90 minutes in an exposure chamber produced symptoms of tightness in the chest and in some cases difficulty in breathing was experienced, particularly upon initial exposure [8]. Subjects were able to tolerate exposure at these levels throughout the 90 minutes' duration of this experiment. In general, exposures of about $2.5 \mathrm{mg} / \mathrm{m}^{3}$ could be tolerated only for a few minutes. These data relate to subjects not previously exposed to CS. There is evidence for the development of some tolerance if exposures are built up slowly with $88 \%$ subjects then being able to tolerate $2.5 \mathrm{mg} / \mathrm{m}^{3}$ for 60 minutes.

\section{CONCLUSION}

Inferential analysis shows that negative correlation between lung function test for FVC with duration of CS exposure whereby for FVC the $r=-0.52, p<0.05(p=0.04)$. In [15] described in their studies showed that nine US marines that was exposed to concentrated CS cloud in a field-training setting for duration of eight weeks resulted having respiratory problems. The result on study of relationship for $\mathrm{FEV}_{1}$ reading with duration of exposure from $\mathrm{CS}$ among the NBC trainers revealed that there is a negative relationship between the variables studied, whereby the $\mathrm{FEV}_{1}$ reading collected in this research will decreases as the duration of exposure to CS increases. Research conducted on personnel who are NBC trainers exposed to CS indicates a negative relationship between lung function tests for $\mathrm{FEV}_{1}$ with duration of exposure to anti-riot agent. Inferential analysis shows that negative correlation between lung 
function test for FVC and FEV1 with duration of CS exposure, whereby $\mathrm{FEV}_{1}$ is $\mathrm{r}=-0.25, \mathrm{p}>$ $0.05(\mathrm{p}=0.04)$. The result to hypotheses four and five indicates that the longer the NBC trainers working in the environment with primary and secondary exposure to CS the lower the $\mathrm{FVC}$ and $\mathrm{FEV}_{1}$ reading recorded that is manifested by chronic lung health problems. More than $51.8 \%$ of the respondents from the NBC trainers group have been involved with gas mask testing training between four to six years' duration with $69 \%$ from the NBC trainers group exposed to CS more than twice a week. Therefore, it can be concluded that this study showed that there is impairment in the lungs of the NBC trainers from aspect of lung health and lung function due to exposure to CS during the gas mask testing training that is conducted in a confined gas mask facility.

\section{REFERENCES}

[1] Arbak P, Başer İ, Kumbasar Ö O, Ülger F, Kılıçaslan Z, Evyapan F. Long term effects of tear gases on respiratory system: Analysis of 93 cases. The Scientific World Journal, 2014, 34(6):345-348

[2] Asuku M E, Milner S M, Gerold K B. Beyond tears: The potential hazards of the o-ChlorobenzylideneMalononitrile (CS) gas under scrutiny. Journal of Special Operations Medicine: A Peer Reviewed Journal for SOF Medical Professionals, 2011, 11(4):28-30

[3] Cheremisinoff N. P. Handbook of air pollution prevention and control. Oxford: Butterworth-Heinemann, 2002

[4] Gautam M P,Ghimire U. Tear gases and health. Journal of Nepal Medical Association, 2004, 43:164-170

[5] Gupta R. C. Handbook of toxicology of chemical warfare agents. Massachusetts: Academic Press, 2009

[6] Hout, J. J., White, D. W., Artino, A. R., Knapik, J. J. o-ChlorobenzylideneMalononitrile (CS) riot control agent associated acute respiratory illnesses in a U.S. army basic combat training cohort.Military Medicine, 2014, 179(7):793-798

[7] Defense Technical Information Center (DTIC). Operations in chemical, biological, radiological, and nuclearenvironments. Virginia: DTIC, 2013 
[8] Park S,Giammona S. Toxic effects of tear gas on an infant following prolonged exposure.American Journal of Diseases of Children, 123(3): 245-246

[9] Patel P D, Patel R K, Patel N J. Review on reactive airways dysfunction syndrome (RADS). Asian Journal of Pharmaceutical and Clinical Research, 2012, 5(3):10-15

[10] Organisation for the Prohibition of Chemical Weapons (OPCW). Article IV-Chemical weapons. The Hague: OPCW, 2005

[11] Pierce R., Johns D. P. The measurement and interpretation of ventilatory function in clinical practices. New York: McGraw-Hill, 2007

[12] Punte C L, Owen E J,Guntentag P J. Exposure to ortho-ChlorobenzylideneMalononitrile. Archives of Environmental Health, 1963, 6(3): 366-374

[13] Sipoli L, Martinez L, Doná ria V S,Probst L. Spirometry in healthy subjects: Do technical details of the test procedure affect the results?Plos One, 2014, 9(9):1-6

[14] Malaysian Army (MA). Manual operasi pertahanan kimia. Kuala Lumpur: MA, 2004

[15] Thomas R J. Acute pulmonary effects from o-ChlorobenzylidenMalononitrile "tear gas": A unique exposure outcome unmasked by strenuous exercise after a military training event. Military Medicine, 2002, 167(2):136-140

[16] Marrs T C, Maynard R L. 23 organic arsenicals. In T. T. Marrs, R. L. Maynard, \& F. Sidell, (Eds.), Chemical warfare agents: Toxicology and treatment. New Jersey: John Wiley and Sons, 2007, pp. 467-476

[17] Hilmas C J, Poole M J, Katos A M, Williams P T. Chapter 11: Riot control agents. In R. C. Gupta (Ed.), Handbook of toxicology of chemical warfare agents. Massachusetts: Academic Press, 2015, pp. 153-175

[18] National Institute for Health and Care Excellence (NICE). Chronic obstructive pulmonary disease inover 16s: Diagnosis and management. London: NICE, 2010

[19] McLean J A, Tobin G. Animal and human calorimetry. England: Cambridge University Press, 2007

\section{How to cite this article:}

Vikneswaran M, Majid N A. The effect of o-chlorobenxylidene malononitrite (cs) to military personals healthfuring nbc training. J. Fundam. Appl. Sci., 2017, 9(3S), 602-620 